\title{
Erratum to: Family Violence and Dating Violence in Korea
}

\author{
Jae Yop Kim • Hee Jin Kim • Jang Won Choi • \\ Clifton Emery
}

Published online: 5 March 2014

(C) Springer Science+Business Media New York 2014

Erratum to: J Fam Viol (2014) 29:23-33

DOI 10.1007/s10896-013-9556-3

The corresponding author, Hee Jin Kim, wishes to correct his affiliation found in the original version of this article. His correct affiliation is shown in the affiliation section below.

The online version of the original article can be found at doi:10.1007/ s10896-013-9556-3.

J. Y. Kim • C. Emery

Graduate School of Social Welfare, Yonsei University, 50 Yonsei-ro,

Seodaemun-gu, Seoul, South Korea 120-749

\section{H. J. Kim $(\bowtie)$}

Public Policy Research Institute, Korea University, 2511 Sejong-ro,

Sejong City, South Korea 339-700

e-mail: kjoie74@gmail.com

J. W. Choi

Social Welfare Research Center, Yonsei University, 50 Yonsei-ro,

Seodaemun-gu, Seoul, South Korea 120-749 